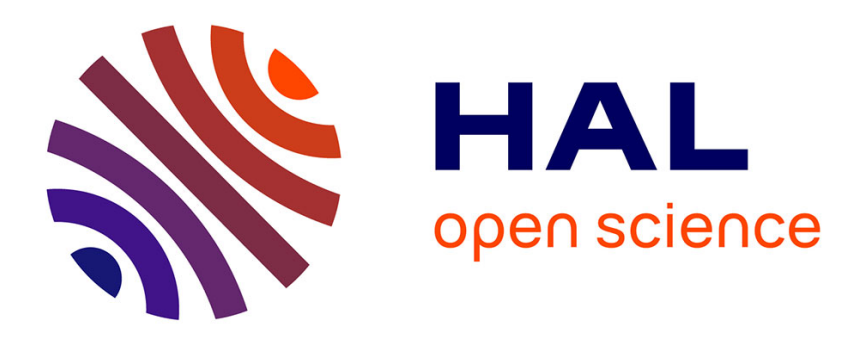

\title{
Solidification kinetics of the particulate metal matrix composite
}

\author{
Z. Konopka, J. Braszczynski
}

\section{To cite this version:}

Z. Konopka, J. Braszczynski. Solidification kinetics of the particulate metal matrix composite. Journal de Physique IV Proceedings, 1993, 03 (C7), pp.C7-1825-C7-1828. 10.1051/jp4:19937290 . jpa00251933

\section{HAL Id: jpa-00251933 https://hal.science/jpa-00251933}

Submitted on 1 Jan 1993

HAL is a multi-disciplinary open access archive for the deposit and dissemination of scientific research documents, whether they are published or not. The documents may come from teaching and research institutions in France or abroad, or from public or private research centers.
L'archive ouverte pluridisciplinaire HAL, est destinée au dépôt et à la diffusion de documents scientifiques de niveau recherche, publiés ou non, émanant des établissements d'enseignement et de recherche français ou étrangers, des laboratoires publics ou privés. 


\title{
Solidification kinetics of the particulate metal matrix composite
}

\author{
Z. KONOPKA and J. BRASZCZYNSKI
}

Technical University of Częstochowa, ul. Dabrowskiego 69, 42-200 Czȩstochowa, Poland

\begin{abstract}
The solidification kinetics of metals and alloys can be investigated by means of the derivative thermal analysis. This method have been used to the solidification investigation of the Cu5\% Pb5\%Ti-graphite composites. The mathematical description of this method for the experimental castings was presented. On the basis obtained equations the rate of the solidification heat emission and the quantity of the solidified phase during this process have been calculated. Comparative measurements of the cooling curves and solidification curves were carried out both the composite and the matrix alloy. Increase of the solidification heat emission rate and the solidification kinetics for composite containing the graphite particles was ascertained in comparision with the solidification of matrix alloy. The hipothesis of the effect of the graphite particles on the composite solidification was presented. The microstructure of the examined composite have been also presented.
\end{abstract}

\section{Introduction}

The copper matrix composites with graphite particles can be used as the bearing material $(1,2)$ and they can be fabricated by casting methods. In this case the solidification process is very important because it forms the structure of castings $(3,4)$. Experimental examination of this process is difficult and the derivative thermal analysis method is very usefull for it. The characteristic parameters of solidification process and its kinetics can be calculated by means of the temperature and its derivative measurements during this process $(5,6)$.

\section{Experimental procedure}

The composites Cu5\%Pb5\%Ti-graphite were fabricated by mechanical mixing of the graphite flakes with liquid metal matrix. The titanium addition allows the liquid metallic phase to wet the graphite flakes and to arrange uniformly these particles in composite. The contents of the graphite particles up to 3 wt pct in composite do not effect on the castability, and so this composite can be fabricated by casting method. The experimental castings were made in the thin - walled shell mould with the thermoelement placed in the centre of this mould.

During the solidification process the change of the temperature $T=f(t)$ and its derivative $d T / d t=f(t)$ were registrated. The solidification kinetics can be calculated by using these curves and suitable mathematical description of this method. 


\section{Mathematical description of method}

The mathematical analysis of solidification process in this mould is possible for the following simplifications.

The thin-walled mould is not able to accumulate of heat and so the intensity of cooling is very small. In this case we can assume that the temperature gradients in casting do not exist. For the solidification of experimental casting the Biott number is equal $B i<0.01$. It is a result of low conduction resistance and of high heat exchange resistance of copper alloys. The temperature is only function of time. Between the surface of casting and mould the hot crack is not existance and the heat exchange proceeds for these conditions in accordance with Newton's boundary conditions.

All coefficients are constant and they do not depend on temperature. The crystallization heat emission is directly proportional to the temperature drop in the solidification range.

Taking into account these assumptions the balance of heat for the casting and the environment can be written. Introducing the surplus of the temperature determined as $\vartheta=T-T_{0}$ and the function of the heat source as $\beta=d I / d t$, the solidification equation may be expressed as follows :

$$
-\frac{\alpha \vartheta}{R p c}+\frac{\beta}{c}=\frac{d \vartheta}{d t}
$$

where: $c$ - specific heat, $R$ - characteristic dimension of the casting, $\alpha$ - overall heat-transfer coefficient, L - latent heat, $\mathrm{T}_{\mathrm{o}}$ - environment temperature, $p$ - density, $t$ - time.

The elements of equation (1) express the rate of the temperarure drop, and so the solidification equation can be written in general form

$$
U_{T G}+U_{T Z}=U_{T}
$$

where: $U_{T G}, U_{T Z}, U_{I}$ - gradient, source and real rate of the temperature drop respectivély.

The quantity $U_{T}$ is directly obtained from the solidification diagram.

The quantity $E_{T G}$ is calculated from the function $\vartheta=E(t)$ which is registrated during the measurements. Then the quantity $U_{T Z}$ is calculated from equation (2) and according with definition the $\beta$ values are calculated.

The real overail-heat transfer coefficient $(\alpha)$ is calculated as the sum of the natural convection coefficient and the radiation coefficient. For the examined systems the value of this coefficient was assumed as constant during the process and its value was $25 \mathrm{~W} / \mathrm{m} 2 \mathrm{~K}$.

The $\beta$ function is correlated with the quantity of the solidified phase fraction $(\eta)$, therefore the kinetic equation of solidification can be obtained:

$$
\eta=\frac{c}{L} \int_{t_{n}}^{t} U_{z Z} d t
$$

where: $t_{n}$ - time of the crystallzation start compling with the liquidus temperature and the volume fraction of graphite particles in composite, $t$ - total time of solidification 


\section{Results}

The curves of self-cooling and their derivatives for the composite and matrix alloy have been shown in Fig.I. The calculated $U_{\text {TG }}$ function has been also presented on this diagrams.

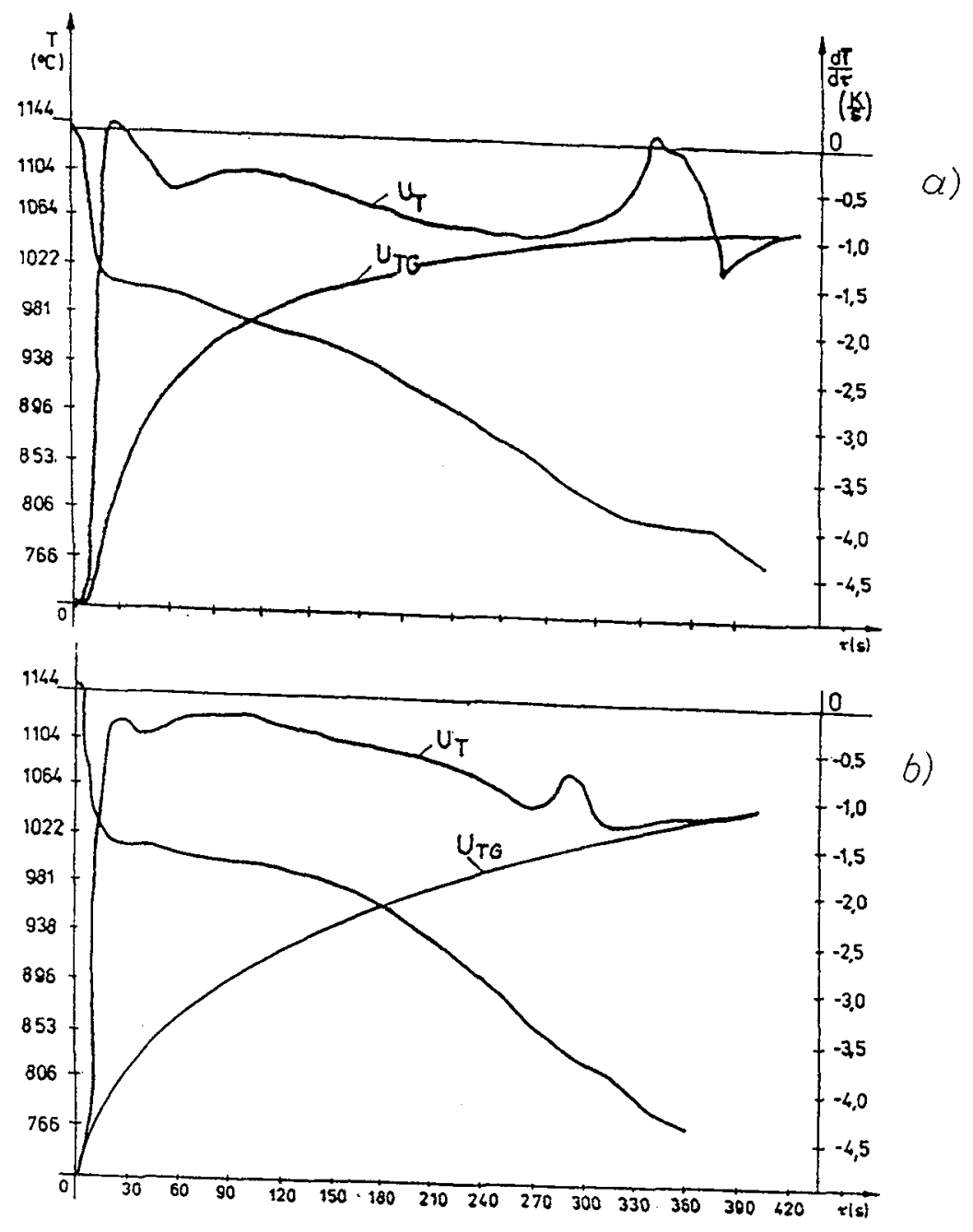

Fig.1. Solidification and cooling curves diagrams. a-composite matrix, b- CuTiPb-graphite.

The characteristic parameters of the solidification process such as the liquidus, solidus temperature, latent heat, solidification time which were used in computer calculations, obtained from the diagram have been determined.

Calculated $\beta$ function values for both the matrix alloy and composite and also the solidification kinetics (eq.3.) have been presented in Fig.2. The structure of examined composite obtained from optical and scanning microscopy has been shown in Fig. 3 . 


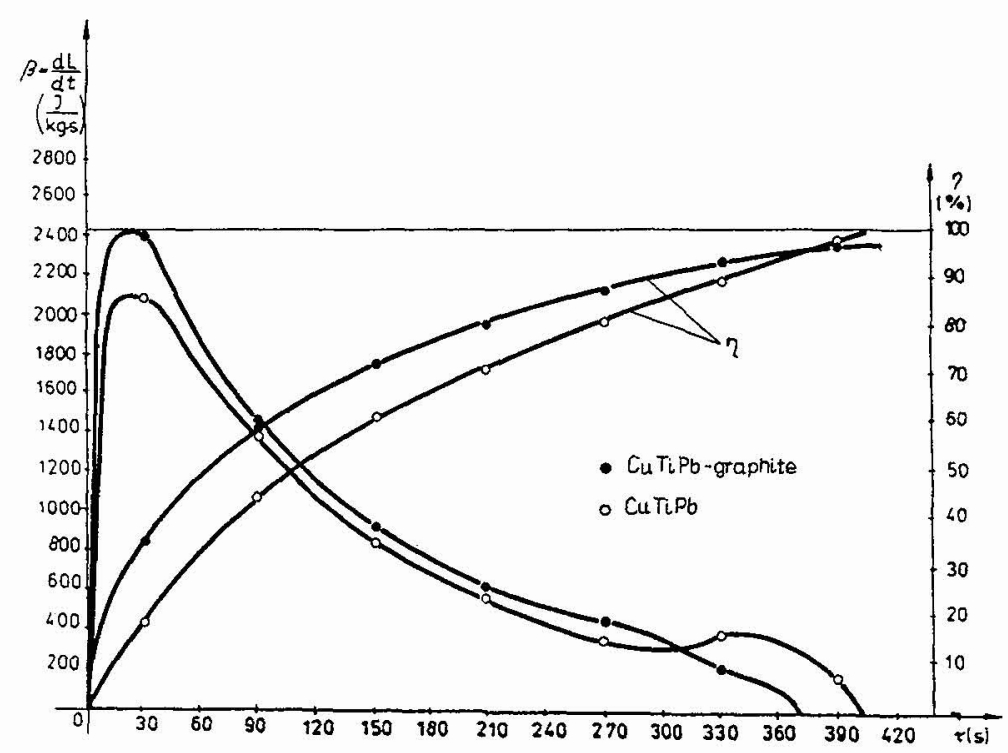

Fig.2.The $\beta$ function values and solidification kinetics.
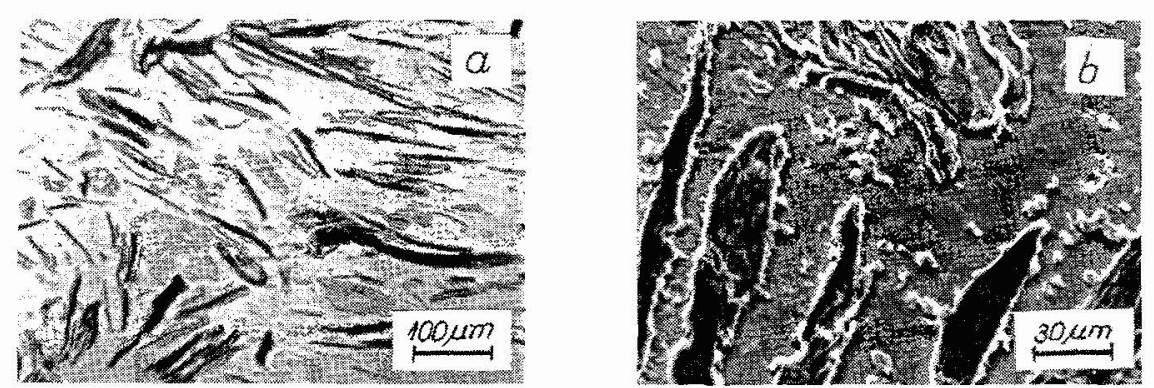

Fig.3.Microstructure of CuTiPb-graphite composite. a-optical view, b-scanning picture.

\section{Conclusions}

The investigation of the solidification process shows that the graphite particles change the kinetics of this process. In initial stage of the crystallization heat emission for composite is more dynamical than this quantity for matrix alloy. Similar dependance is observed for the $n$ quantity. Probably these effects are concerned with the graphite which can be nucleus in crystallization. Metallographic observations and measurements show that the solid solution phase Cu, $\mathrm{Ti}$ crystailizes around the each graphite flake. These examinations confirm the results of solidification and mechanism of this process.

References

1) TRUMPEL R.L. Metals and Materials (1987), 3.

2) SCHWARTZ M.M. Composite Materials Handbook.Mc Graw-Hil1, (1984).

3) WENDLANDT $W$. Thermal Methods of Analysis.John Willey and Sons (1974).

4) FLEMINGS A. Solidification Processing.Mc Graw-Hill (1974).

5) RABUS D.POLTEN S. Giesserei-Rundschau 9 (1972), 12 ..

6) ABIJEIDINGER K.STRIZIK P. Fonderie 342 (1975) 59. 